\title{
Electrohydrolysis of Olive Mill Wastewater: Effect of Applied DC Voltage
}

\author{
Canan Can Yarımtepe ${ }^{1,2, *}$, Nilgün Ayman $\mathrm{Oz}^{2,3}$ and Orhan Ince ${ }^{1}$
}

\begin{abstract}
The aim of this study is the investigation of electrohydrolysis treatment process for olive mill wastewater in terms of pollutants removal and hydrogen production. For this purpose, Different voltages including 4, 6 and $8 \mathrm{~V} \mathrm{DC}$ were tested for 3 hours. $8 \mathrm{~V} \mathrm{DC}$ for 3 hours was found to be as the most effective condition. At this optimum voltage, different time periods were also investigated. At $8 \mathrm{~V}$, significant pollutant removal efficiencies were obtained. $68 \%$ turbidity, $70 \%$ TSS, $52 \%$ COD and 19\% sCOD removal efficiencies were achieved. Volume of produced gas was $1500 \pm 10 \mathrm{ml}$ and hydrogen percent was determined as $85 \%$. Hydrogen production along with pollutant removal is one of the advantages of electrohydrolysis. Therefore, electrohydrolysis can be proposed as a feasible alternative treatment step for wastewaters which is characterized by high organic matter and also suspended matter.
\end{abstract}

Keywords - Electrohydrolysis, Hydrogen production, Olive mill wastewater, Pollutant removal.

\section{INTRODUCTION}

$\mathrm{M}$ ARMARA region including Canakkale is one of the main parts for olive oil production in Turkey. Olive mill wastewater (OMW), has high amount of organic matter and also toxic/ inhibitory compounds such as lipids and phenolic compounds. Therefore it is not easy to treat such strong wastewater with conventional treatment processes.

In literature, several treatment options and strategies including; centrifuge [1], evaporation [2], filtration [3], ecoagulation [4]-[5] and applying to land [6] have been proposed for management of olive mill wastewater. Besides these methods; advanced treatment processes such as ozonation [7]-[8]-[9], photocatalysis [10], electrocoagulation [5]-[11], fenton oxidation [12], ozone and fenton oxidation [13] and wet air oxidation [14] have been tested for olive mill wastewater treatment. However, these processes have a disadvantage of either high operating costs or high sludge quantities which requires additional treatment thereby additional investment and operating cost. Therefore, it has been proposed combined methods comprising of pretreatment unit and advanced treatment steps for olive mill wastewater in order to facilitate the degradation of complex organic matters

Canan Can Yarımtepe, Istanbul Technical University, Istanbul, Turkiye (00905052960172; canancan16@gmail.com)

Nilgün Ayman Oz, Canakkale Onsekiz Mart Universitesi, Canakkale, Turkiye, (nilgunayman@comu.edu.tr).

Orhan Ince, Istanbul Technical University, Istanbul, Turkiye. (inceor@itu.edu.tr). and reduction of toxic and inhibitory substances. Chemical, physicochemical, enzymatic and thermal oxidation processes are commonly used as pre-treatment step for OMW.

In recent years, electrohydrolysis (EH) studies has gained momentum as an effective method to produce hydrogen energy from different waste/wastewaters with simultaneous pollutant removal[15]. The main advantages of process are energy efficiency [15], simple equipment, easy operation, environmental compatibility, low capital and low operating cost [16]-[17].

Therefore, the aim of this study is the investigation of electrohydrolysis treatment of OMW in terms of removal of pollutants and simultaneously hydrogen production.

\section{MATERIALS AND METHODS}

Olive mill wastewater samples which were used in this study, were obtained from TARİ̧ Geyikli Olive Processing Factory in December, 2014 as a composite sample. The characterization of Olive mill wastewater sample is given in Table 1.

TABLE I

WASTEWATER COMPOSITION

\begin{tabular}{lll}
\hline \hline Parameters & Unit & Wastewater Sample* \\
\hline Ph & & 4,991 \\
Conductivity & $\mu \mathrm{s} / \mathrm{cm}^{2}$ & 13950 \\
Turbidity & $\mathrm{NTU}$ & $16100 \pm 35$ \\
Color & $\mathrm{ptCO}$ & $38200 \pm 42$ \\
$\mathrm{TS}$ & $\mathrm{mg} / \mathrm{L}$ & $48544 \pm 200$ \\
$\mathrm{TVS}$ & $\mathrm{mg} / \mathrm{L}$ & $41272 \pm 160$ \\
$\mathrm{TSS}$ & $\mathrm{mg} / \mathrm{L}$ & $20900 \pm 60$ \\
VSS & $\mathrm{mg} / \mathrm{L}$ & $19600 \pm 50$ \\
$\mathrm{COD}$ & $\mathrm{mg} / \mathrm{L}$ & $87716 \pm 135$ \\
TOC & $\mathrm{mg} / \mathrm{L}$ & $23883 \pm 20$ \\
SCOD & $\mathrm{mg} / \mathrm{L}$ & $40306 \pm 45$ \\
Total Phenol & $\mathrm{mg} / \mathrm{L}$ & $6560 \pm 50$ \\
\hline \hline
\end{tabular}

Electrohydrolysis was performed in glass reactors $(1 \mathrm{~L}$ capacity) with consists a cover supporting two parallel aluminium electrodes. Experimental set up is given in Fig. 1. 


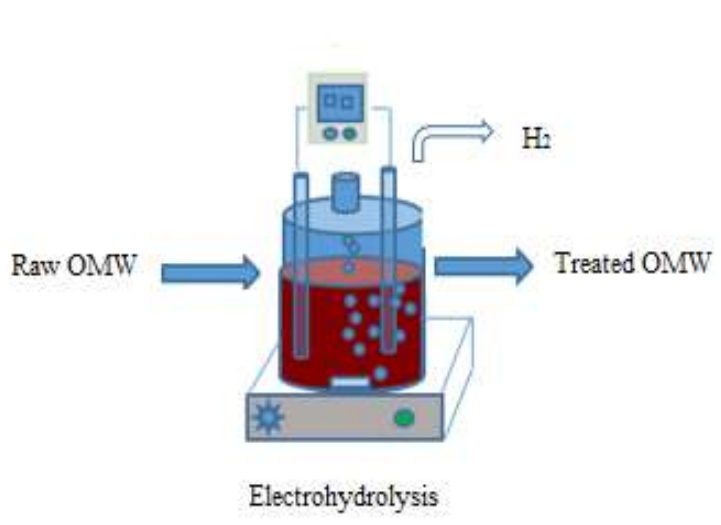

Fig. 1. Experimental set-up

Selection of electrode type is the main part of an electrochemical process and it is directly related to removal efficiencies. The most common electrode materials for electrohydrolysis are aluminium and iron because they are cheap, readily available and effective. In this study, aluminium electrodes are selected according to previous studies. Sample volume was $500 \mathrm{ml}$ for experiment. There were $2 \mathrm{~cm}$ distance between electrodes and $2 \mathrm{~cm}$ distance between the electrodes which allowed easy stirring of the effluent. A direct current with different voltages including 2, 4, 6 and 8 voltages were tested by using a power supply (TT-T-ECHNI-C MCH-305DII) for different reaction periods. During the experiments, the change in voltage and the current were monitored by multimeter (UNI-T UT61D Digital Modern Multimeters UT61D AC/DC Tester). After electrohydrolysis process, the samples were allowed to settle down during 12 hours. The supernatant were used for determination of pollutants' concentrations. During the process, produced gas was controlled with gas counters and hydrogen yield of produced gas was determined by GC.

\section{RESULTS AND DISCUSSION}

In electrohydrolysis; 4, 6 and $8 \mathrm{~V}$ DC were examined for different duration until three hours in order to determine optimum conditions for both hydrogen gas production and pollutant removal efficiencies. Further electrohydrolysis durations could not be applied to the wastewater due to the excessive foaming and floatation of suspended solids found in OMW at high concentration. The supernatant were used to determine of pollutant concentrations according to standard methods. The changes in olive mill wastewater samples after electrohydrolysis process are summarized in Table 2. As seen in Table II., COD removal efficiencies were enhanced while applied DC voltage was increased 4 to $8 \mathrm{~V}$. However after 8 $\mathrm{V}$; further increases in applied DC voltages, were not significantly improved the effluent COD concentrations. Therefore at $8 \mathrm{~V}$ direct current which is selected as optimal DC voltage; $68 \%$ turbidity, $70 \%$ TSS, $52 \%$ COD and $19 \%$ sCOD removal efficiencies were obtained.
TABLE II

Wastewater Composition AfTer Ec PRETREATMENT

\begin{tabular}{llll}
\hline \hline & \multicolumn{3}{c}{ Direct Voltage, V } \\
\hline Parameters & 4 & 6 & 8 \\
Ph & 6,188 & 6,344 & 6,592 \\
Conductivity & 12360 & 12490 & 13170 \\
Turbidity & 1900 & 1600 & 1500 \\
Color & 13300 & 11500 & 11400 \\
TS & 47400 & 31524 & 18160 \\
TVS & 37168 & 20700 & 11632 \\
TSS & 3700 & 3450 & 3250 \\
COD & 50290 & 45676 & 42498 \\
SCOD & 40016 & 35870 & 32563 \\
Total Phenol & 1852 & 1755 & 1641 \\
\hline \hline
\end{tabular}

When pollutant removal efficiencies were evaluated, it is obvious that most of the organic matter were removed with different mechanisms during the electrohydrolysis process for OMW. There is only two studies which electrohydrolysis experiments were carried out in a Plexiglas bottle with aluminium electrodes for OMW. [18] were investigate the treatment of olive mill wastewater with electrohydrolysis with $0-10 \mathrm{~V}$, using three aluminium electrodes as anodes and four as cathodes. The optimum condition, $76 \%$ of COD, $91 \%$ of polyphenol and $95 \%$ of dark colour removal efficiencies were reported. [19] investigated different DC voltages with aluminium electrodes $(0.5-4.0 \mathrm{~V})$ for OMW treatment. When DC voltage was increased to $2 \mathrm{~V}$ as optimum condition, $44 \%$ COD removal efficiency was achivied.

During electrohydrolysis; reaction duration is one of the main parameters in terms of both removal efficiencies and operational cost [20]. Electrohydrolysis experiments were carried out at different durations $(30,60,90,120,150$ and 180 min) in order to determine the reaction time effect. Fig. 2 shows change in concentration of main pollutants (COD, SCOD and TSS) for different duration at optimum DC which is $8 \mathrm{~V}$..

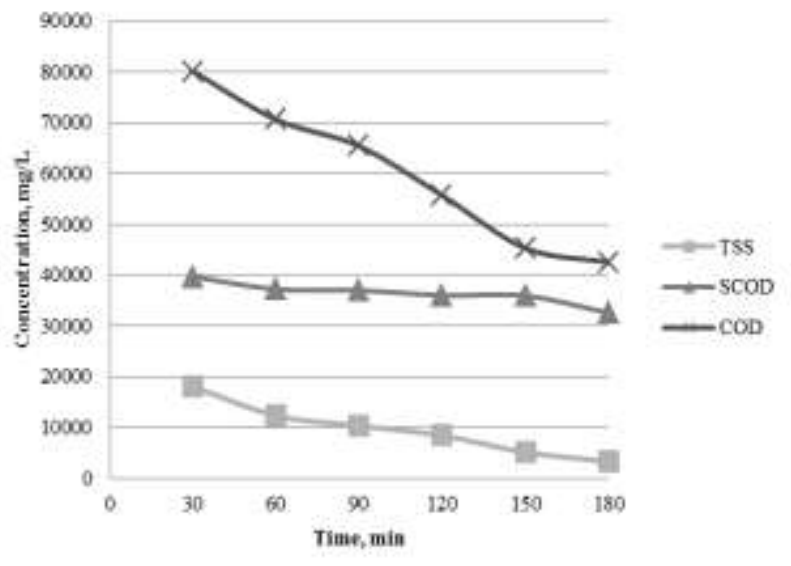

Fig. 2. Pollutant concentrations for different reaction time 
As seen from Fig 2.; best removal efficiencies were obtained using 3 hours electrohydrolysis process. Therefore, 3 hours was selected as optimum duration for EH of OMW.

Fig. 3. shows cumulative gas production during electrohydrolysis process. The production of hydrogen gas is an important indicator of electrohydrolysis process in terms of organic matter removal. It has been stated that current determines bubble production rate, bubble size and the flocs growth which affect the efficiency of the electrohydrolysis process. [21]. Hydrogen gas production increased with increasing in DC voltage and reached the highest level (1500 $\mathrm{ml} \mathrm{H} 2$ ) at $8 \mathrm{~V} \mathrm{DC}$ voltage for three hours.

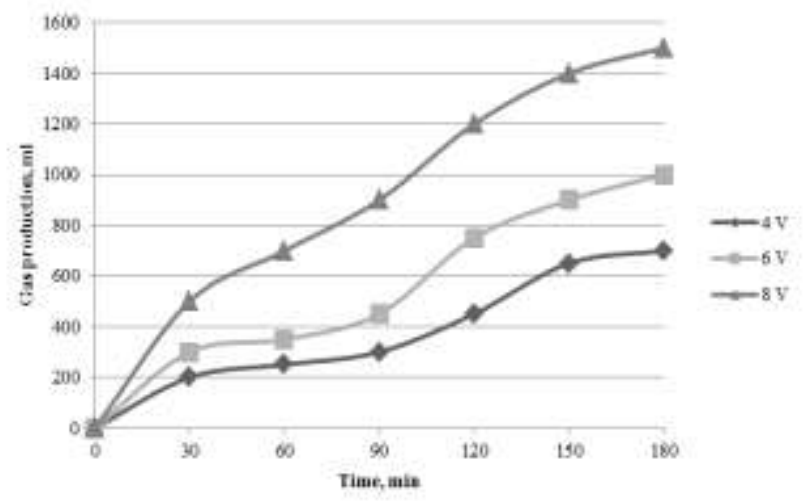

Fig 3. Gas production during EC

There is a little increase in hydrogen content of gas in different conditions. During the experiments, hydrogen yield of the gas were determined as $85 \%, 87 \%$, and $88 \%$ for $4 \mathrm{~V}, 6$ $\mathrm{V}$ and $8 \mathrm{~V}$ current voltage, respectively. There is only $4 \%$ increase in hydrogen content of gas at $8 \mathrm{~V}$ when compared to 4 V.

In Table III. reported studies about electrohydrolysis of different industrial wastewaters were summarized

TABLE III

STUDIES ON ELECTROHYDROLYSIS OF DIFFERENT WWS

\begin{tabular}{|c|c|c|c|c|c|}
\hline Wastewater & $\begin{array}{l}\text { DC } \\
\text { Voltage, } \\
\text { V }\end{array}$ & $\begin{array}{l}\text { Time, } \\
\text { Hour }\end{array}$ & $\begin{array}{l}\text { COD } \\
\text { removal, } \\
\%\end{array}$ & $\begin{array}{l}\text { Hydrogen } \\
\text { yield, } \\
\mathrm{L} \mathrm{H}_{2} / \mathrm{g} \\
\mathrm{COD}_{\text {rem }} \\
\end{array}$ & Ref \\
\hline OMW & 4 & 96 & 44 & 55 & [19] \\
\hline Leachate & 5 & 96 & 77 & 40 & [22] \\
\hline $\begin{array}{l}\text { Vinegar } \\
\text { wastewater }\end{array}$ & 4 & 96 & 12 & 27 & [23] \\
\hline OMW & 8 & 3 & 52 & 33 & $\begin{array}{l}\text { Our } \\
\text { study }\end{array}$ \\
\hline
\end{tabular}

As seen from Table, in this study, unlike reported studies, better COD removal efficiency was achieved with higher DC voltage in shorter reaction duration. The studies in the literature were carried out at lower DC voltages (4-5 V) for longer period of time (96 hours). COD removal efficiencies were reported as between $12 \%$ for vinegar wastewater and $77 \%$ for leachate. For OMW, COD removal efficiency has been reported as $44 \%$ at $4 \mathrm{~V}$ DC for 96 hours [19]. In our study, COD removal efficiency has been determined as $52 \%$ with OMW. The difference between the results could be attributed to the different initial characteristics of wastewaters

\section{CONCLUSION}

In this study, electrohydrolysis is proved to be an efficient process for OMW with 70\% TSS, 52\% COD and 19\% sCOD removal efficiencies in optimum condition $(8 \mathrm{~V} \mathrm{DC}$ for three hours). Based on the results; a considerable amount of organic matter and suspended solids were removed with the application of electrohydrolysis to OMW. Therefore, the efficiency of electrohydrolysis were found to be satisfactory for such a high strength wastewater in a low treatment time period. In spite of this statement, the method can not be proposed as a whole treatment scheme in order to maintain discharge standards, however, it can be used as pretreatment step for facilitating successive alternative treatment processes. According to obtained data, electrohydrolysis process was found to be relatively more environmental friendly process compared to other treatment alternatives for OMW since $\mathrm{pH}$ adjustment is not required and high amount of chemical sludge is not produced. Moreover, hydrogen gas production, which is a clean energy source, from wastewaters is another advantage for management of OMW

\section{ACKNOWLEDGMENT}

Financial support by The Scientific and Technological Research Council of Turkey (TUBITAK) was gratefully acknowledged (Project No.: 114Y179)..

\section{REFERENCES}

[1]E. Turano, S. Curcio, M. G. De Paola, V. Calabrò, and G. Iorio, "An integrated centrifugation-ultrafiltration system in the treatment of olive mill wastewater,” J. Memb. Sci., vol. 209, no. 2, pp. 519-531, 2002.

[2]F. Masi, R. Bresciani, G. Munz, and C. Lubello, "Evaporation condensation of olive mill wastewater: Evaluation of condensate treatability through SBR and constructed Wetlands," Ecol. Eng., vol. 80, pp. 6-11, 2014. [3]A. Ginos, T. Manios, and D. Mantzavinos, "Treatment of olive mill effluents by coagulation-flocculation-hydrogen peroxide oxidation and effect on phytotoxicity,” J. Hazard. Mater., vol. 133, no. 1-3, pp. 135-142, 2006.

[4]S. Khoufi, F. Aloui, and S. Sayadi, "Treatment of olive oil mill wastewater by combined process electro-Fenton reaction and anaerobic digestion," Water Res., vol. 40, no. 10, pp. 2007-2016, 2006.

[5]Ü. Tezcan Ün, S. Uğur, A. S. Koparal, and Ü. Bakir Öğütveren, "Electrocoagulation of olive mill wastewaters," Sep. Purif. Technol., vol. 52, no. 1 , pp. 136-141, 2006.

[6]I. Sabbah, T. Marsook, and S. Basheer, "The effect of pretreatment on anaerobic activity of olive mill wastewater using batch and continuous systems," Process Biochem, vol. 39, pp. 1947-1951, 2004.

[7]F. J. Benitez, J. Beltran-Heredia, J. Torregrosa, and J. L. Acero, "Improvement of the anaerobic biodegradation of olive mill wastewaters by prior ozonation pretreatment," Bioprocess Eng., vol. 17, no. 3, pp. 169-175, 1997.

[8]R. Andreozzi, G. Longo, M. Majone, and G. Modesti, "Integrated treatment of olive oil mill effluents (OME): Study of ozonation coupled with anaerobic digestion," Water Res., vol. 32, no. 8, pp. 2357-2364, 1998.

[9]A. M. Amat, A. Arques, H. Beneyto, A. García, M. A. Miranda, and S. Seguí, "Ozonisation coupled with biological degradation for treatment of phenolic pollutants: A mechanistically based study," Chemosphere, vol. 53, no. 1, pp. 79-86, 2003. 
[10] W. Gernjak et al., "Pilot-plant treatment of olive mill wastewater (OMW) by solar TiO 2 photocatalysis and solar photo-Fenton," Sol. Energy, vol. 77, no. 5, pp. 567-572, 2004.

[11] F. Hanafi, O. Assobhei, and M. Mountadar, "Detoxification and discoloration of Moroccan olive mill wastewater by electrocoagulation," J. Hazard. Mater., vol. 174, no. 1-3, pp. 807-812, 2010.

[12] F. J. Rivas, O. Gimeno, J. R. Portela, E. M. De Ossa, and F. J. Beltra, "Supercritical Water Oxidation of Olive Oil Mill Wastewater," Ind. Eng. Chem. Res., vol. 40, pp. 3670-3674, 2001.

[13] B. Kiril Mert, T. Yonar, M. Yalili Kiliç, and K. Kestioğlu, "Pretreatment studies on olive oil mill effluent using physicochemical, Fenton and Fenton-like oxidations processes," J. Hazard. Mater., vol. 174, no. 1-3, pp. 122-128, 2010.

[14] D. Pham Minh, P. Gallezot, S. Azabou, S. Sayadi, and M. Besson, "Catalytic wet air oxidation of olive oil mill effluents. 4. Treatment and detoxification of real effluents," Appl. Catal. B Environ., vol. 84, no. 3-4, pp. 749-757, 2008.

[15] F. Kargi, "Comparison of different electrodes in hydrogen gas production from electrohydrolysis of wastewater organics using photovoltaic cells (PVC)," Int. J. Hydrogen Energy, vol. 36, no. 5, pp. 3450-3456, 2011.

[16] F. Shen, X. Chen, P. Gao, and G. Chen, "Electrochemical removal of fluoride ions from industrial wastewater," Chem. Eng. Sci., vol. 58, no. 3-6, pp. 987-993, 2003.

[17] X. Chen, G. Chen, and P. L. Yue, "Separation of pollutants from restaurant wastewater by electrocoagulation," Sep. Purif. Technol., vol. 19, no. 1-2, pp. 65-76, 2000.

[18] N. Adhoum and L. Monser, "Decolourization and removal of phenolic compounds from olive mill wastewater by electrocoagulation," Chem. Eng. Process. Process Intensif., vol. 43, no. 10, pp. 1281-1287, 2004.

[19] F. Kargi and E. C. Catalkaya, "Hydrogen gas production from olive mill wastewater by electrohydrolysis with simultaneous COD removal," Int. J. Hydrogen Energy, vol. 36, no. 5, pp. 3457-3464, 2011.

[20] T. Coskun, F. Ilhan, N. M. Demir, E. Debik, and U. Kurt, "Optimization of energy costs in the pretreatment of olive mill wastewaters by electrocoagulation," Environ. Technol., vol. 33, no. 7, pp. 801-807, 2012.

[21] M. Kobya, O. T. Can, and M. Bayramoglu, "Treatment of textile wastewaters by electrocoagulation using iron and aluminum electrodes," J. Hazard. Mater., vol. 100, no. 1-3, pp. 163-178, 2003.

[22] F. Kargi and E. C. Catalkaya, "Electrohydrolysis of landfill leachate organics for hydrogen gas production and COD removal," Int. J. Hydrogen Energy, vol. 36, no. 14, pp. 8252-8260, 2011.

[23] F. Kargi and S. Arikan, "Improved hydrogen gas production in electrohydrolysis of vinegar fermentation wastewater by scrap aluminum and salt addition,” Int. J. Hydrogen Energy, vol. 38, no. 11, pp. 4389-4396, 2013. 